\section{ENVIRONMENTALLY FRIENDLY ASPIRATOR}

Hygotip XL Bio is an environmentally friendly aspirator fitting $16 \mathrm{~mm}$ systems. It is manufactured from autoclavable bio-based plastic made of sugar canes. Unlike conventional plastics where fossil raw materials such as oil and natural gas are used, sugar cane is a completely renewable resource. The large diameter of $16 \mathrm{~mm}$ gives a high suction capacity and is more efficient in absorbing aerosols near the source. The sturdy design works as a tongue holder, enabling the practitioner to retract the cheek and providing good accessibility.

The Hygotip XL Bio is very patient friendly with the specially designed ventilation grooves at the connection point of the aspirator. This prevents it from getting stuck to the soft tissue with discomfort for the patient.

For more information, visit www.orsing.se.

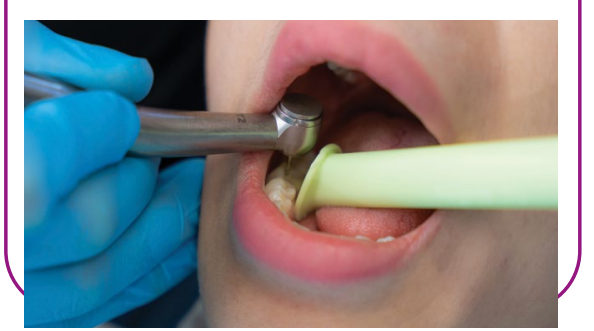

\title{
PEPPERMINT TOOTHPASTE TABLETS
}

High quality, environmentally friendly with a fresh clean feeling: this is what patients want from their toothpaste tablet. No longer do you have to compromise between protecting your oral health and protecting our planet.

With Tongue's peppermint toothpaste tablets, your patients can feel good about protecting their oral health with 1,450 ppm fluoride and protecting our planet with one less plastic toothpaste tube ending up in landfill.

Tongue's toothpaste tablet pouches are home compostable and delivered direct to your door through your letterbox, making the switch from traditional toothpaste to toothpaste tablets simple, easy and cost effective.

Simply chew the toothpaste tablet for a few seconds, moisten your manual or electric toothbrush bristles with water and brush your teeth as normal. You can also add a compostable bamboo toothbrush with replaceable heads to your order for the full eco-friendly dental experience.

Tongue's was founded by UK qualified dentists with the mission of helping to put an end to the plastic crisis in dentistry. They wanted to develop a range of eco-friendly dental products which they would feel confident recommending to their patients without any compromise to their patients' oral health.

For more information visit www. tonguesclub.com. If you are interested in stocking Tongue's eco-friendly dental products in your practice, contact hello@ tonguesclub.com.

\section{LOW-COST PEOPLE-COUNTER FOR DENTAL SURGERIES}

The company behind some of the UK's most exciting and dynamic interactive exhibition displays in visitor attractions and museums has brought to market QCounter - a fully automated, but low-cost, access control/ people-counter system. Businesses emerging from lockdown restrictions must limit the number of people accessing a space or building to ensure the site remains COVID-safe and compliant with government regulations.

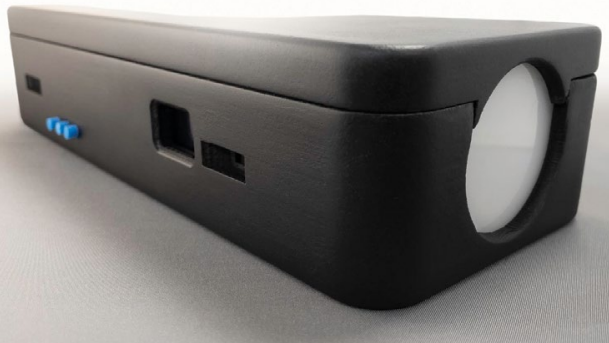

QCounter, based on a traffic light system, is a fully automated (without the need for any human operation), 'Plug n' Play' customer/ visitor/staff counting system that manages and ensures the safe flow of people through spaces - thus ensuring organisations remain COVID-safe whilst fully operational.

QCounter provides the following functionality:

- Fully automated - no staff/personnel remote control operation required (unlike other systems)

- Ergonomic design

- Large bright indication of status (based on traffic light system)

- Integrated LCD information display

- Easy-to-change number of people allowed

- Powered by dc supply from mains plug or USB power bank

- Portable and easy to mount to any standard retractable barrier post - no tools required
- Both single and dual units versions available - works on one way system with separate in and out doors

- Client-branded 'dashboard' webpage (for public visibility).

Operational benefits for client:

- Compliance with COVID secure rules

- Visual reassurance for customers/ visitors/staff/guests

- Non-language specific

- GDPR compliant (no integrated cameras)

- Webpage can be displayed on larger screen to further reassure compliance

- Expansion options available.

The units have been designed and manufactured in the UK by UK conceptto-reality company FifeX and are available to order today from their dedicated website www.qcounter.co.uk. 